Running head: IMPLICIT SELF-ESTEEM IN OLDER ADULTS

\title{
Assessment of Implicit Self-Esteem in Older Adults: The Role of Actual and Ideal Self- Esteem in Negative Mood.
}

Ineke Demeyer $^{1}$, Nuria Romero ${ }^{1}$ and Rudi De Raedt ${ }^{1}$

\author{
${ }^{1}$ Department of Experimental Clinical and Health Psychology, \\ Ghent University, Ghent, Belgium \\ Ineke.Demeyer@UGent.be \\ Nuria.RomeroMartin@UGent.be \\ Rudi.Deraedt@ugent.be
}

\begin{abstract}
Author Note
Correspondence concerning this article should be addressed to Ineke Demeyer, Ghent

University, Department of Experimental Clinical and Health Psychology, Henri Dunantlaan 2

B-9000 Ghent, Belgium, Tel: + 32926494 11, Fax: + 32926464 89, E-mail:

Ineke.Demeyer@UGent.be
\end{abstract}

\section{Funding}

This research was supported by the Flemish research fund FWO [G015614N] and by the Psychopathology and Information Processing in Older Adults (PIPO) BOF alliance grant [IV1: I/00125/01]. 


\begin{abstract}
The interplay between actual and ideal self-esteem may be a key component in emotional disorders. Since automatic self-evaluations are not always consciously accessible, assessment through implicit measures is necessary. Given the lack of implicit self-esteem measures in late life, we aimed to identify a reliable measure and to clarify the role of actual and ideal selfesteem in mood and depressive symptoms in older adults. Forty-nine older adults completed two adapted Go/No go Association tasks measuring implicit actual and ideal self-esteem and measures of mood and depressive symptoms. The two GNAT tasks showed satisfactory internal consistency. Moderation analyses revealed that lower actual self-esteem in older adults is related to higher levels of sad mood when ideal self-esteem is high. Moreover, lower actual self-esteem is related to more anxious mood. Given the role of self-esteem in emotional wellbeing, a reliable measure for older adults is crucial to improve age-appropriate diagnostics and treatment.
\end{abstract}

Key words: older adults, self-esteem, implicit measure, depression, negative mood 


\section{Assessment of Implicit Self-Esteem in Older Adults: The Role of Actual and Ideal Self- Esteem in Negative Mood.}

Self-esteem is a powerful construct that has been implicated in many psychological processes and emotional disorders. It can be defined as thoughts, feelings and evaluations of the self and has a strong relationship with emotional well-being (e.g. Crocker \& Park, 2004). More specifically, self-esteem is stated to be an important factor in the onset, maintenance and relapse of depression (e.g. Beck, Rush, Shaw \& Emery, 1979) and it can even predict future depressive symptomatology (Sowislo, Orth, Meier, 2014). Moreover, self-esteem is closely associated with several Big Five personality factors (Erdle, 2013). For instance, individuals with higher self-esteem report higher levels of emotional stability, agreeableness and conscientiousness (Zeigler-Hill et al., 2015). Accordingly, low self-esteem is often a core characteristic in personality disorders, such as borderline and avoidant personality disorders (e.g. Lynum, Wilberg, \& Karterud, 2008). Given the key role of self-esteem in this broad spectrum of psychological disorders, it is an important target of clinical treatment. However, this treatment relies on valid tools for assessing self-esteem that can be used for individuals in different stages of development.

Research into the life course trajectory of self-esteem shows that self-esteem increases until the age of 60 and afterwards starts declining in old age (Orth, Trzesniewski, \& Robins, 2010). This study by Orth and colleagues indicates that this decline in self-esteem results from age-related changes in physical health (i.e. declining health, reduced mobility) and socioeconomic status (i.e. changes in income, loss of employment status). Moreover, a recent study has shown that decreased self-esteem in older adults contributes to increased cortisol secretion when experiencing stress, but that increased self-esteem protects older adults from this change in cortisol output (Liu, Wrosch, Miller, \& Pruessner, 2014). Based on the findings 
of Baumeister, Campbell, Krueger \& Vohs (2003) indicating that self-esteem is related to adaptive coping with stress, Liu et al. (2014) assumed that increased self-esteem in older adults can buffer the effect of stress on changes in cortisol secretion through improved coping mechanisms. Thus, given that old age represents a critical developmental stage in maintaining a high level of self-esteem and targeting improved self-esteem in older adults may increase adaptive coping with stress, assessing changes in self-esteem in older adults can be crucial.

However, research into the role of self-esteem in older adults and into age-appropriate ways to assess this construct is still limited. The few studies that investigated self-esteem in old age (e.g. Orth, Robins, Trzesniewski, Maes, \& Schmitt, 2009; Gana, Bailly, Saada, Broc, \& Alaphilippe, 2015) have focused on self-reported self-esteem and examined whether the relationship between self-esteem and depression varies across the life span or whether this association occurs regardless of age. Orth and colleagues (2009) found that low self-esteem remains a risk factor for subsequent depressive symptoms across the life span, even at old age. In contrast, Gana, and colleagues (2015) found stability in self-esteem and depression in older adults, and concluded that self-esteem does not predict depressive mood in old age. However, Gana et al. (2015) highlight that the use of self-report measures to investigate self-esteem in older adults may have led to a limited view on self-esteem and therefore important information about the relationship between self-esteem and depression might be missing. To date no research has yet investigated different types of measures of self-esteem in older adults.

In search of different ways to assess self-esteem, it has been found that only implicit measures but not explicit measures predict future depressive symptoms in samples of formerly depressed and never depressed adults (Franck, De Raedt, \& De Houwer, 2007). This can be explained by the fact that dysfunctional beliefs about the self are not always consciously accessible (e.g. Beck et al., 1979). Thus, self-report measures are not only susceptible to several response biases (i.e. social desirability), but they are also unable to assess the more automatic 
spontaneous beliefs about the self (De Houwer, Teige-Mocigemba, Spruyt, \& Moors, 2009). This highlights the need for implicit measures in order to obtain crucial information about selfesteem.

In younger adult studies, several tasks have been used to investigate implicit selfesteem. Former research relied on implicit measures that looked at reaction times on different associations between self-concepts and positive/negative concepts, such as the Implicit Associations Test (IAT, Greenwald and Farnham, 2000). This way, participants cannot control the assessment and they may not even be aware of what was measured. However, using these tasks the expected link between lower implicit self-esteem and depression was not consistently found (e.g. De Raedt, Schacht, Franck \& De Houwer, 2006, Franck, De Raedt \& De Houwer, 2008). There were even indications for more positive implicit self-esteem in participants vulnerable to depression (Frack et al., 2008). To clarify these conflicting results, Remue, De Houwer, Barnes-Holmes, Vanderhasselt, and De Raedt (2013) argued that the traditional implicit self-esteem measures only offer insights into the relationship between the concepts of 'self' and 'positive/negative', but not on how these concepts are related or on how they are interpreted by the participants. More specifically, both actual self (i.e. the evaluation of the current self) and ideal self (i.e. the evaluation of the desired characteristics of the self) are implicated when measuring the abovementioned association between 'self' and 'positive/negative'. Thus, the unexpected findings of higher positive self-esteem in samples vulnerable to depression do not necessarily point towards higher positive actual self-esteem but may reflect higher positive ideal self-esteem such as having higher standards of how a person would like to be. Remue et al. (2013) emphasized that actual and ideal self need to be differentiated by adding propositional information to the implicit measures, such as 'I am' for actual self-esteem and 'I want to be' for ideal self-esteem. Using the implicit relational assessment procedure (IRAP) with these propositions, they found that dysphoric participants 
demonstrated lower actual self-esteem and higher ideal self-esteem compared to a healthy control group. In a later study, these authors again confirmed the importance of differentiating between actual and ideal self-esteem and found that healthy adults did not differ in their level of actual and ideal self-esteem, but dysphorics had lower actual self-esteem compared to their ideal self-esteem (Remue, Hughes, De Houwer, \& De Raedt, 2014).

Even though the relationship between implicit actual ('I am good') and ideal ('I want to be good') self-esteem has been identified as an important component in emotional disorders and assessing self-esteem may be especially important during later stages in life in light of the possible declines brought by various age-related losses, there has been no research into the suitability of these implicit measures in older adults. Psychometric improvements in assessing self-esteem may lead to improved insights in the role of self-esteem in later stages of life and may result in optimized diagnostics and treatment for psychological distress in older adults. Since there has been no research focussing on implicit self-esteem in older adults, the main goals of this study were to investigate the reliability of a measure to assess implicit self-esteem in older adults, and to gain knowledge on the interaction of actual and ideal self-esteem in relationship with mood and depressive symptomatology in older adults.

The first research aim of this study was to explore the feasibility and reliability of an implicit measure of actual and ideal self-esteem in an older adult sample. In contrast to previous studies, we decided not to use the IRAP because of the high difficulty level and high attrition rate of this task in younger (undergraduate) samples (e.g. Remue et al., 2013). Since older adults samples are known for their motoric slowing, the IRAP might not be suitable because a high percentage of the older adults sample might be excluded for not reaching the acquired accuracy and speed thresholds. Instead, we opted for the adapted Go/No go Association task (GNAT), which has been developed to measure automatic attitudes and preferences (Nosek \& Banaji, 2001) and was recently adapted to measure implicit self-esteem in clinically depressed samples 
(Romero, Sanchez, Vazquez \& Valiente, 2016). The advantage of this task is that it is less complex for participants compared to the IRAP. In the GNAT, one word appears in the centre of the screen and participants only have to respond by pressing the space bar when this word belongs to one of the two informative labels presented in the upper corners of the screen (i.e. self or not self, negative or positive). In line with previous studies (Remue et al., 2013; Remue et al., 2014), we decided to use two versions of the GNAT: one using the proposition 'I am' to measure actual self-esteem and one using the proposition 'I want to be' to measure ideal selfesteem. We expected that these tasks would have an acceptable attrition rate and good internal consistency in an older adult sample.

The second research aim was to investigate if the interaction between actual and ideal implicit self-esteem is associated with mood and depressive symptomatology in older adults. Focussing on the interaction instead of the difference between actual and ideal implicit selfesteem will allow to specify the nature and relevance of the difference between actual and ideal self-esteem. In line with Remue et al. (2013), we hypothesized that the relationship between actual self-esteem and negative mood/depressive symptoms would be moderated by ideal selfesteem. More specifically, we expected that lower actual self-esteem in older adults would be associated with higher levels of negative mood and more depressive symptoms when ideal selfesteem is high.

\section{Method}

\section{Participants}

Older adults over the age of 65 were recruited through several recreational organisations. A total of 60 older adults (31 females and 29 males) participated in this study. Based on screening, 1 participant was excluded because of a low score on cognitive abilities (MMSE, see further). As a result of technical problems $(\mathrm{N}=2)$ or the decision of participants 
not to continue the task $(\mathrm{N}=8)$, self-esteem data of 10 participants were incomplete and therefore excluded from analyses. Analyses were performed on the 49 remaining participants (28 females and 21 males) with a mean age of 72.73 years $(S D=4.92$, range $65-85) .55 .1 \%$ was married or living together, $14.3 \%$ was divorced, $8.2 \%$ was single and $22.4 \%$ was widow(er). Moreover, $16.3 \%$ did not complete high school, $32.7 \%$ had a high school diploma and $51 \%$ had a higher education degree. All participants signed informed consent and were reimbursed 20 euros for their participation.

\section{Materials}

Mini Mental State Examination (MMSE). This interview allows screening for cognitive impairments (Folstein, Folstein \& McHugh, 1975). Scores can range from 0 to 30, with higher scores indicating better cognitive functioning. Only participants scoring above the conventional cut-off score of 24 (Folstein et al., 1975) were included in the study, which led to the exclusion of 1 participant.

The Beck Depression Inventory (BDI-II-NL). The Dutch version of the BDI-II (Beck, Steer, \& Brown, 1996) was used to measure the presence and the severity of depressive symptoms. Participants rate the severity of 21 depressive symptoms on a scale ranging from 0 to 3. The BDI-II-NL is known to have acceptable psychometric criteria (Van der Does, 2002) and also in our older adult sample the scale demonstrated good internal consistency with a Cronbach's Alpha of .86.

Visual Analogue Scale (VAS). VASs were used to assess current mood and consisted of two statements: 'How sad do you feel at this moment?' and 'How anxious do you feel at this moment?'. Participants were asked to place a mark on a $100 \mathrm{~mm}$ line to indicate their level of agreement with each statement. This line was labelled on opposite ends: 'not at all' at the left and 'extremely' at the right. Participants' responses were scored by measuring the distance from 
the left of the line to the marked point with ' 0 ' being the lowest score and ' 100 ' being the highest score.

The Implicit Self-Esteem Task. Two adapted versions of the Go/No go Association task (GNAT; Nosek \& Banaji, 2001) were used to measure both implicit actual and implicit ideal self-esteem (Romero, Remue, Sanchez \& De Raedt, 2016). The task was administered on a DELL laptop with a 17 inch screen and an AZERTY keyboard. Both tasks used the same 12 attributes (6 positive and 6 negative words), but differed in the 2 target categories that were used. For the actual self GNAT task, the target categories were 'I am' and 'I am not'. For the ideal self GNAT task, the target categories were 'I want to be' and 'I don't want to be'. These tasks assessed the strength of the automatic associations between these categories and positive (e.g. 'competent', 'successful') or negative (e.g. 'useless', 'worthless') attributes. These attributes were selected based on previous studies evaluating implicit actual and ideal selfesteem (Remue, et al., 2013; Remue et al., 2014)

Both GNAT tasks consisted of four blocks that were presented in random order using Inquisit Millisecond software. A block consisted of 14 practice trials and 52 critical trials. Each trial started with the presentation of an attribute (i.e. 'I am') or target category (a positive or negative word) in the centre of the screen. In the upper left and right corners of the screen, two informative labels about the correct responses were presented throughout the task. For the actual self-esteem task, the left label refers to the target category ('I am' or 'I am not') and the right label refers to the type of attributes (positive or negative). Participants were asked to press the space bar as quickly as possible when the centred word refers to one of the two labels and not to respond when the word did not match one of the labels. For instance, in one block the labels 'I am' and 'positive' are presented in the upper corners of the screen. During that block participants would have to press the space bar when centred words referred to the 'I am' category or when a positive attribute is presented. However if the centred words referred to a 
negative attribute, participants did not have to respond. Centred words remained on screen until participants pressed the space bar or until $1200 \mathrm{~ms}$ elapsed. Participants received feedback after each trial: a green ' $\mathrm{O}$ ' appeared in the centre of the screen when the response was correct or a red ' $\mathrm{X}$ ' was shown when the response was incorrect. Each block used a different combination of target category and attribute labels: I am-Positive, I am-Negative, I am not-Positive, and I am not-Negative. The order of those four blocks was counterbalanced across participants. Based on the actual self-esteem task, two self-esteem indices were calculated. The consistent actual self-esteem index was calculated by summing up the average reaction time in the I am-Positive block and the average reaction time in the I am not-Negative block and dividing it by 2. Similar, the inconsistent actual self-esteem index was based on the sum of the average reaction time in the I am-Negative block and the average reaction time in the I am not-Positive block divided by 2 . With these indexes, we created an implicit actual self-esteem index by subtracting average reaction time in the actual inconsistent condition from the average reaction time in the actual consistent condition (in line with Romero et al., 2016). A positive score on this implicit actual self-esteem index reflects the participant's tendency to associate the actual self more easily to positive than negative attributes and is thus indicative of a positive actual self-esteem.

The ideal self-esteem task used almost the same procedure except that the target categories 'I am' and 'I am not' were replaced by 'I want to be' and 'I don't want to be'. Also for this task, a consistent and an inconsistent ideal self-esteem index can be calculated using the same method as in the actual self-esteem task. Similarly, we calculated an implicit ideal self-esteem index by subtracting the average reaction time in the ideal inconsistent condition from the average reaction time in the ideal consistent condition. A positive score on this index reflects a positive ideal self-esteem. The order of actual and ideal self-esteem tasks was counterbalanced across participants.

\section{Procedure}


This experiment was part of a larger older adult study ${ }^{1}$, which was approved by the faculty's ethics committee. After informed consent, participants completed the actual and ideal self-esteem tasks (in random order). Afterwards, the VAS's were filled in. Finally, the MMSE was taken and participants completed the BDI-II. At the end, all participants were debriefed.

\section{Results}

\section{Participant Characteristics}

Means and standard deviations for all explicit and implicit variables are presented in Table 1. There were no significant differences for any variables between male and female participants, all $\mathrm{t}<1.05$, all $\mathrm{p}>.30$.

\section{Reliability}

First, we investigated the split-half reliability of the GNAT task by dividing the task in two based on even and uneven trials. For the actual GNAT, Spearman-Brown split-half correlation value was .97 for actual consistent and .97 for actual inconsistent. For the ideal GNAT, Spearman-Brown split-half correlation value was .96 for ideal consistent and .96 for ideal inconsistent. Finally, for the combined scores (consistent minus inconsistent), SpearmanBrown split-half correlation value was still .55 for the actual index ${ }^{2}$ and .51 for the ideal index. In line with research on experimental tasks, these values indicate satisfactory reliability for both tasks.

\section{Depressive Symptoms and Actual versus Ideal Self-esteem}

In order to investigate whether ideal self-esteem moderates the relationship between actual self-esteem and depressive symptoms, we performed a hierarchical multiple regression analysis following the approach of Aiken and West (1991). The actual and ideal self-esteem variables were centered and their interaction was calculated by multiplying these centered scores. In the regression analyses with depressive symptoms as dependent variable, the centered 
scores of actual and ideal self-esteem were entered in the first step and their interaction in the second step. However, there were no significant main or interaction effects (all $t\langle 1.65, p\rangle$ $.11)$.

\section{Current Negative Mood and Actual versus Ideal Self-esteem}

In order to investigate whether ideal self-esteem moderates the relationship between actual self-esteem and sad mood, we again performed a hierarchical multiple regression analysis as described above. In the regression analyses with sad mood as dependent variable, the centered scores of actual and ideal self-esteem were entered in the first step and their interaction in the second step. This analysis revealed that although both actual and ideal selfesteem did not predict sad mood (all $p>.12$ ), the interaction term predicted sad mood nearly significantly, $t=-1.90, p=.06, \beta=-.27, b=-.005, \mathrm{CI}=[-.01, .001]$, and added a nearly significant increase in explained variance to the model, $\Delta R^{2}=.07, p=.06$. The results of this hierarchical multiple regression analysis can be found in Table 2. To clarify this moderation effect, we used Hayes and Matthes' SPSS macro (2009) to estimate the conditional effects of actual self-esteem on the outcome variable at low (one SD below the mean), moderate (sample mean), and high (one SD above the mean) values of ideal self-esteem. These results are plotted in Figure 1. The analysis showed a negative relationship between actual self-esteem and sad mood at high levels of ideal self-esteem, $t=-2.25, p=.03, b=-.31$, whereas there was no significant relationship between actual self-esteem and sad mood at low and moderate levels of ideal self-esteem (all $p>$.12). These results indicate that lower actual self-esteem leads to higher levels of sad mood when ideal self-esteem was high.

Finally, we examined the moderation effects of ideal self-esteem on the relationship between actual self-esteem and anxious mood. In the regression analyses with anxious mood as dependent variable, the centered scores of actual and ideal self-esteem were entered in the first step and their interaction in the second step. Analysis revealed that actual self-esteem predicted 
higher levels of anxious mood, $t=-2.95, p<.01, \beta=-.39, b=-.34, \mathrm{CI}=[-.60,-.11]$. However, ideal self-esteem did not significantly predict anxious mood nor did the interaction term added to the explained variance of the model (all $p>.28$ ). Thus, these results indicate that lower actual self-esteem was related to higher anxious mood levels. Table 3 shows the results of this regression analysis.

\section{Discussion}

The purpose of the present study was to investigate the feasibility, the reliability and the relationship with mood of an innovative implicit measure for assessing actual and ideal selfesteem in older adults. We administered two adapted Go/No go Association tasks in an older adult sample and examined internal consistency of this implicit self-esteem measure. Furthermore, we administered self-report measures of current mood and depressive symptoms to investigate the role of actual and ideal self-esteem as well as of its interaction on older adults' emotional wellbeing. Based on previous research in younger samples (e.g. Remue et al., 2013), we expected that ideal self-esteem would moderate the relationship between actual self-esteem and mood/ depressive symptoms.

First, when investigating the psychometric criteria of this novel assessment tool for older adults, we found that both the actual and the ideal self-esteem measures demonstrated satisfactory internal consistency. In line with the good psychometric properties of the selfesteem GNAT found in younger adults samples (Romero et al., 2016), these findings demonstrate the reliability of the task in an older adult sample. This indicates that the task can be implemented as an age-appropriate tool for assessing both implicit actual and ideal selfesteem.

Second, in line with expectations based on previous research in younger adults (Remue et al., 2013; Remue et al., 2014), our findings indicate that the interplay between actual and 
ideal self-esteem can be important in relationship to emotional well-being. Moderation analyses revealed a trend significant negative relationship between actual self-esteem and sad mood at high levels of ideal self-esteem. Lower actual self-esteem in healthy older adults was related to higher levels of sad mood only when ideal self-esteem was high. Just as in younger adults (e.g. Remue et al., 2013), lower actual self-esteem may only lead to negative emotions when it contrasts high aspirations for oneself. In contrast, analyses only showed a negative relationship between actual self-esteem and anxious mood. Lower actual self-esteem was related to higher levels of anxious mood, but was not related to ideal self-esteem. We hypothesize that current sad mood is more closely related to depressive symptomatology than anxious mood, which might explain why previous results on the interplay between low actual self-esteem and high ideal self-esteem (e.g. Remue et al., 2013) are only indicated by the sad mood scale. Although our findings specify implicit actual self-esteem as an important correlate to anxious mood, further research is needed to investigate whether this finding can be replicated in older adults with more stable anxious traits. Anyway, these results demonstrate that the differentiation between actual and ideal in the concept of self-esteem may lead to improved insights into its role in emotional well-being.

Notably, we found no significant results when examining the relationship between actual/ideal self-esteem and depressive symptomatology as measured with the Beck Depression Inventory. However, in contrast to Remue et al. (2013, 2014) who did demonstrate this relationship in subclinically depressed samples, we used a sample of healthy older adults with a low variability in depressive symptoms. Future studies using samples with a larger variability in depressive symptoms as well as studies comparing older and younger adult clinical samples are important to further investigate whether the relationship between depression and the interplay between actual and ideal implicit self-esteem varies across the life span. Moreover, 
future research into implicit self-esteem in older adults should not only focus on clinical populations with depression, but also on clinical populations with anxiety disorders.

Thus, both findings from internal consistency and external validity with current negative mood indicate that this assessment tool may be suitable for older adults. Given the changes in self-esteem in older adults (Orth et al., 2010), an age-appropriate assessment tool is necessary to assist further investigation looking to clarify the role of self esteem in old age. Furthermore, concerning the importance of self-esteem in emotional wellbeing and several psychological disorders, such as depression and personality disorders (e.g. Sowislo et al., 2014; Zeigler-Hill et al., 2015), a reliable measure of the different constructs of implicit self-esteem might lead to improved diagnostics and result in more precisely targeted treatment for older adults. More specifically, it can lead to a specific treatment focus on either what the patients thinks about himself/herself or how the patient beliefs he/she should be.

Although this study is an important first investigation into the assessment and role of implicit self-esteem in old age, it has some limitations. First, we only tested healthy older adults without major cognitive problems as indicated by the MMSE as a first step to assess the feasibility of this implicit measure in this age group. Even though the task demands of the GNAT seem to be less complex than previously used tasks (i.e. IRAP), 8 participants chose to stop the task before it was finished. This demonstrates that it is still a demanding task for older adults and that we need to investigate feasibility and replicate reliability in clinical older adult populations. Future research may need using more sensitive measures of cognitive functioning, in order to clarify the role of mild cognitive deficits in the feasibility of the GNAT. Second, other reliability and validity indexes were not investigated. For instance, we did not include a measure of explicit self-esteem to examine congruent validity with our implicit task. However, previous studies have demonstrated that implicit and explicit measures of self-esteem do not necessarily correlate (e.g. Remue et al., 2014) and it has been argued that this discrepancy 
between implicit and explicit measures of self-esteem is a another part of emotional-wellbeing, as it is also associated with depressive symptoms and feeling lonely (Creemers, Scholte, Engels, Prinstein, \& Wiers, 2012). Finally, since this study used a correlational design to investigate whether there was a relationship between mood and the new implicit self-esteem measure, we cannot make any conclusions about the causal relationships between mood and implicit selfesteem. Moreover, future research using an experimental design is needed to investigate whether the task may have an influence on mood.

In summary, this is, to our knowledge, the first study to investigate an implicit measure of assessing self-esteem in older adults. Even though implicit assessment may offer valuable information about self-evaluations that are not consciously accessible, studies into ageappropriate assessment were lacking. Our findings indicate that the adapted Go/No go Association task can be a reliable measure of implicit self-esteem in older adults. Moreover, the present study emphasized the importance of differentiating between actual and ideal selfesteem as the discrepancy between low actual and high ideal self-esteem in healthy older adults may be related to higher levels of sad mood. Advancements in the assessment of self-esteem are important in light of the role of self-esteem in psychological disorders and may therefore lead to better targeted treatment for older adults. 


\section{References}

Aiken, L.S., \& West, S.G. (1991). Multiple regression: Testing and interpreting interactions. Newburry Park: Sage.

Baumeister, R. F., Campbell, J. D., Krueger, J. I., \& Vohs, K. D. (2003). Does high selfesteem cause better performance, interpersonal success, happiness, or healthier lifestyles? Psychological Science, 1-44.

Beck, A.T., Rush, A.J., Shaw, B.F., \& Emery, G. (1979). Cognitieve therapy of depression. New York, NY: Guilford Press.

Beck, A. T., Steer, R. A., \& Brown, G. K. (1996). Manual for the Beck depression inventory, second edition. San Antonio, TX: The Psychological Corporation.

Creemers, D. H. M., Scholte, R. H. J., Engels, R., Prinstein, M. J., \& Wiers, R. W. (2012). Implicit and explicit self-esteem as concurrent predictors of suicidal ideation, depressive symptoms, and loneliness. Journal of Behavior Therapy and Experimental Psychiatry, 43(1), 638-646. doi: 10.1016/j.jbtep.2011.09.006

Crocker, J., \& Park, L. E. (2004). The costly pursuit of self-esteem. Psychological Bulletin, 130, 392-414. doi: 10.1037/0033-2909.130.3.392

De Houwer, J., Teige-Mocigemba, S., Spruyt, A., \& Moors, A. (2009). Implicit Measures: A Normative Analysis and Review. Psychological Bulletin, 135(3), 347-368. doi: $10.1037 / \mathrm{a} 0014211$

De Raedt, R., Schacht, R., Franck, E., \& De Houwer, J. (2006). Self-esteem and depression revisited: Implicit positive self-esteem in depressed patients? Behaviour Research and Therapy, 44, 1017-1028. doi: DOI 10.1016/j.brat.2005.08.003

Erdle, S. (2013). Self-esteem and higher-order factors of personality: A reply to Simsek. Personality and Individual Differences, 54, 545-546. doi: 10.1016/j.paid.2012.10.030 
Folstein, M. F., Folstein, S. E., \& McHugh, P.R. (1975). 'Mini-mental state'. A practical method for grading the cognitive state of patients for the clinician. Journal of Psychiatric Research, 12, 189-198. doi: 10.1016/0022-3956(75)90026-6

Franck, E., De Raedt, R., \& De Houwer, J. (2007). Implicit but not explicit self-esteem predicts future depressive symptomatology. Behaviour Research and Therapy, 45, 2448-2455. doi: 10.1016/j.brat.2007.01.008

Franck, E., De Raedt, R., \& De Houwer, J. (2008). Activation of latent self-schemas as a cognitive vulnerability factor for depression: the potential role of implicit self-esteem. Cognition and Emotion, 22, 1588-1599. doi: 10.1080/02699930801921271

Gana, K., Bailly, N., Saada, Y., Broc, G., \& Alaphilippe, D. (2015). Relationship between self-esteem and depressive mood in old age: Results from a six-year longitudinal study. Personality and Individual Differences, 82, 169-174. doi: 10.1016/j.paid.2015.03.021

Greenwald, A. G., \& Farnham, S. D. (2000). Using the implicit association test to measure self-esteem and self-concept. Journal of Personality and Social Psychology, 79, 10221038. doi: 10.1037//0022-3514.79.6.1022

Hayes, A.F., \& Matthes, J. (2009). Computational procedures for probing interactions in OLS and logistic regression: SPSS and SAS implementations. Behavior Research Methods, 41, 924-936. doi: 10.3758/BRM.41.3.924

Liu, S. Y., Wrosch, C., Miller, G. E., \& Pruessner, J. C. (2014). Self-esteem change and diurnal cortisol secretion in older adulthood. Psychoneuroendocrinology, 41, 111-120. doi: 10.1016/j.psyneuen.2013.12.010

Lynum, L. I., Wilberg, T., \& Karterud, S. (2008). Self-esteem in patients with borderline and avoidant personality disorders. Scandinavian Journal of Psychology, 49, 469-477. doi:10.1111/j.1467-9450.2008.00655.x 
Nosek, B. A., \& Banaji, M. R. (2001). The Go/No-go Association Task. Social Cognition, 19, 625-666. doi: 10.1521/soco.19.6.625.20886

Orth, U., Robins, R. W., Trzesniewski, K. H., Maes, J., \& Schmitt, M. (2009). Low SelfEsteem Is a Risk Factor for Depressive Symptoms From Young Adulthood to Old Age. Journal of Abnormal Psychology, 118, 472-478. doi: 10.1037/a0015922

Orth, U., Trzesniewski, K. H., \& Robins, R. W. (2010). Self-Esteem Development From Young Adulthood to Old Age: A Cohort-Sequential Longitudinal Study. Journal of Personality and Social Psychology, 98, 645-658. doi: 10.1037/a0018769

Remue, J., De Houwer, J., Barnes-Holmes, D., Vanderhasselt, M. A., \& De Raedt, R. (2013). Self-esteem revisited: Performance on the implicit relational assessment procedure as a measure of self-versus ideal self-related cognitions in dysphoria. Cognition \& Emotion, 27, 1441-1449.

Remue, J., Hughes, S., De Houwer, J., \& De Raedt, R. (2014). To Be or Want to Be: Disentangling the Role of Actual versus Ideal Self in Implicit Self-Esteem. Plos One, 9. doi: 10.1371/journal.pone.0108837

Romero, N., Sanchez, A., Vazquez, C., \& Valiente C. (2016). Explicit self-esteem mediates the relationship between implicit self-esteem and memory biases in major depression. Psychiatrie Research, 242, 336-344. doi:10.1016/j.psychres.2016.06.003

Romero, N., Remue, J., Sanchez, A., \& De Raedt (2016). Associations between ruminative thinking and actual vs. ideal implicit self-esteem discrepancies in dysphoria. Unpublished work.

Sowislo, J. F., Orth, U., \& Meier, L. L. (2014). What Constitutes Vulnerable Self-Esteem? Comparing the Prospective Effects of Low, Unstable, and Contingent Self-Esteem on Depressive Symptoms. Journal of Abnormal Psychology, 123(4), 737-753. doi: $10.1037 / \mathrm{a} 0037770$ 
Van der Does, A. J. W. (2002). De Nederlandse versie van de Beck Depression Inventory -

Tweede Editie. [The dutch version of the Beck Depression Inventory - Second Edition]. Lisse, The Netherlands: Swets \& Zeitlinger.

Zeigler-Hill, V., Holden, C. J., Enjaian, B., Southard, A. C., Besser, A., Li, H. J., \& Zhang, Q. L. (2015). Self-Esteem Instability and Personality: The Connections Between Feelings of Self-Worth and the Big Five Dimensions of Personality. Personality and Social Psychology Bulletin, 41, 183-198. doi: 10.1177/0146167214559719 


\section{Footnotes}

1 The data for this study were gathered in a larger experiment with older adults. Participants also completed measures on attentional deployment, expectations, personality and positive mood. All these measures were completed after the self-esteem tasks and the negative mood VAS's.

${ }^{2}$ When the actual index was split for creating two new indexes with the even and uneven trials, we found that the actual uneven index was not normally distributed due to one extreme outlier. This participant was removed for the reliability analysis of the actual index. 
Figure 1. The regression lines derived from estimating the different conditional effects of actual self-esteem on sad mood at low, moderate, and high values of ideal self-esteem. 


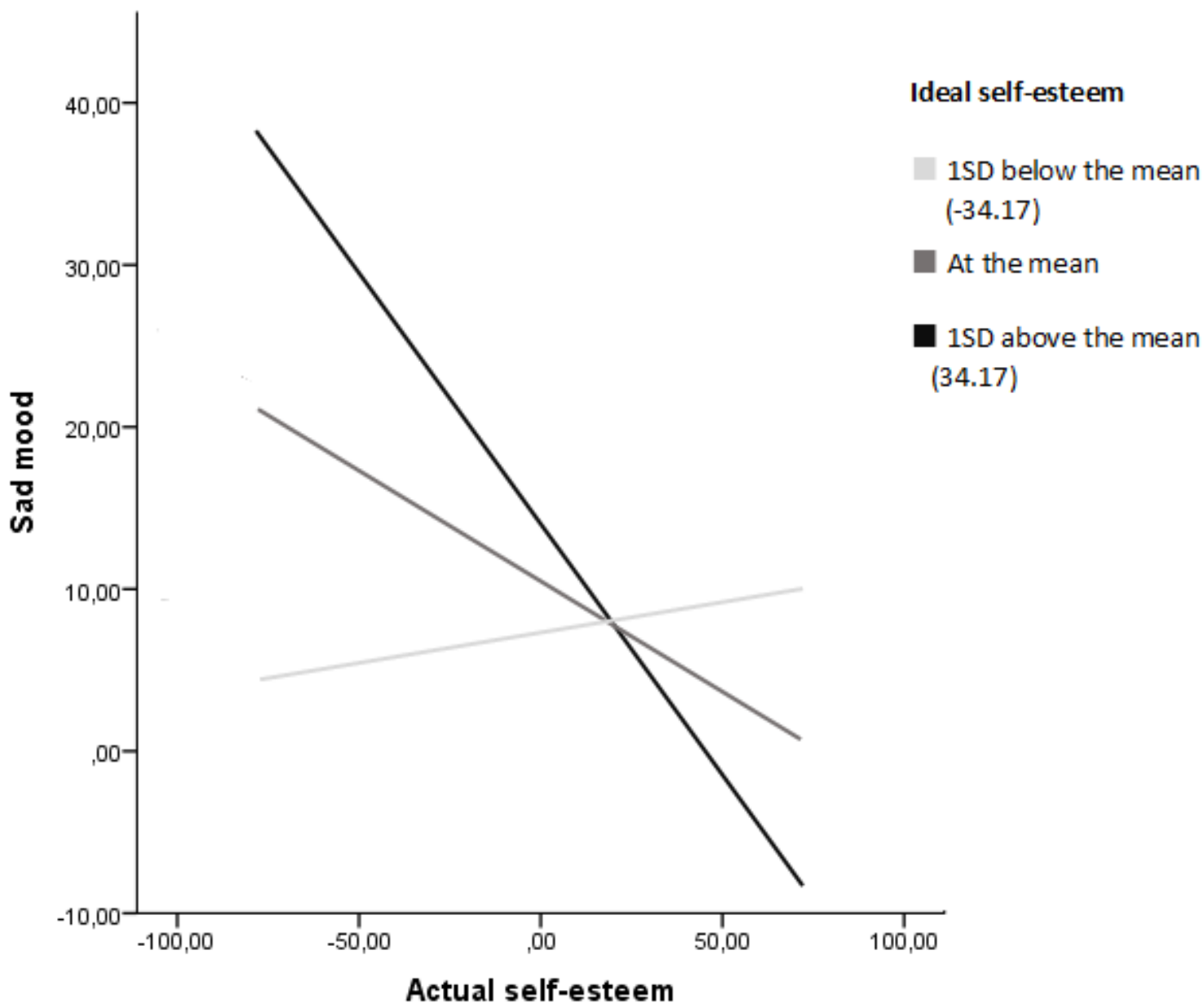


Table 1.

Mean and standard deviations of implicit self-esteem variables, negative mood and depressive symptoms.

\begin{tabular}{lrr}
\hline \multicolumn{1}{c}{ variable } & M & SD \\
\hline BDI-II-NL & 8,71 & 6,43 \\
VAS Sad & 11,71 & 19,65 \\
VAS Stress & 20,49 & 28,50 \\
actual consistent (ms) & 601,02 & 86,96 \\
actual inconsistent (ms) & 619,02 & 95,26 \\
ideal consistent (ms) & 628,16 & 86,52 \\
ideal inconsistent (ms) & 650,71 & 88,96 \\
actual self-esteem index & 18.01 & 32.59 \\
ideal self-esteem index & 22.55 & 34.17 \\
\hline
\end{tabular}

Note. $M=$ Mean; $S D=$ Standard Deviation; $B D I-I I-N L=$ Beck Depression Inventory (Dutch version); VAS= Visual Analogue Scale; ms=milliseconds. 
Table 2.

Results of the hierarchical multiple regression analysis of actual and ideal self-esteem and their interaction on sad mood.

\begin{tabular}{lcccccc}
\hline & \multicolumn{3}{c}{ Model 1 } & \multicolumn{3}{c}{ Model 2 } \\
\cline { 2 - 8 } Variable & $B$ & $\beta$ & $t$ & $B$ & $\beta$ & $t$ \\
\hline Actual SE & -.10 & -.17 & 1.19 & -.14 & -.23 & 1.63 \\
Ideal SE & .12 & .22 & 1.52 & .12 & .20 & 1.48 \\
Actual SE x Ideal SE & & & & -.01 & -.27 & $1.90^{\circ}$ \\
\hline Note. SE $=$ Self-esteem; $\mathrm{R}^{2}=.08$ for Model 1, $\mathrm{p}=.15 ; \mathrm{R}^{2} \Delta=.07$ for Model 2, $\mathrm{R}^{2}=$ \\
$.15, \mathrm{p}=.06$ \\
$* p<.05,{ }^{\circ} p<.07$
\end{tabular}




\section{Table 3.}

Results of the hierarchical multiple regression analysis of actual and ideal self-esteem and their interaction on anxious mood.

\begin{tabular}{|c|c|c|c|c|c|c|}
\hline \multirow[b]{2}{*}{ Variable } & \multicolumn{3}{|c|}{ Model 1} & \multicolumn{3}{|c|}{ Model 2} \\
\hline & $B$ & $\beta$ & $t$ & $B$ & $\beta$ & $t$ \\
\hline Actual SE & -.34 & -.39 & $2.95 * *$ & -.36 & -.41 & $2.95 * *$ \\
\hline Ideal SE & .12 & .15 & 1.10 & .12 & .14 & 1.07 \\
\hline Actual SE x Ideal SE & & & & -.01 & -.06 & .46 \\
\hline $\begin{array}{l}\text { Note. } \mathrm{SE}=\text { self-esteem } \\
.18, \mathrm{p}=.02 \\
*_{p}<.05, * * p<.01\end{array}$ & .1 & & $<.01$ & & Mode & $\mathrm{R}^{2}=$ \\
\hline
\end{tabular}

